Fullagar, S (2009) Negotiating the neurochemical self: Anti-depressant consumption in women's recovery from depression, Health: An Interdisciplinary Journal for the Social Study of Health, Illness and Medicine, 13(3), 377-394.

\begin{abstract}
Anti-depressant treatment can be viewed as an exercise of bio-power that is articulated through policies and practices aimed at the reduction of depression, population health care costs and effects on labour force productivity. Drawing upon a feminist governmentality perspective this article examines the discourses that shaped women's experiences of anti-depressant medication in an Australian qualitative study on recovery from depression. The majority of women had been prescribed antidepressants to treat a chemical imbalance in the brain, manage symptoms and restore normal functioning. One third of participants identified anti-depressants as helpful in their recovery, while two thirds were either highly ambivalent about, or critical of, medication as a solution to depression. 31 women who identified the 'positive' benefits of anti-depressants actively governed themselves as biomedical consumers seeking to redress a chemical imbalance. The problem of depression, the emergence of molecular science and the push for pharmacological solutions are contributing to the discursive formation of new subject positions - such as the neurochemically deficient self (Rose, 2007). Three themes were identified in relation to medication use that included restoring normality, signifying recovery success and control/uncertainty. Anti-depressant medication offered women a normalised pathway to successful recovery that stood in stark contrast to the biologically deficient and morally failing self. These women's stories importantly reveal the gender relations and paradoxes arising from biopolitical technologies that shape selfhood for women in advanced liberal societies.
\end{abstract}

Keywords: depression, neurochemical self, gender, biopower, anti-depressants 


\section{Negotiating the neurochemical self: Anti-depressant consumption in women's recovery from depression}

\section{Introduction}

This article explores the use of anti-depressant medication through the discursive practices that women employ to govern their experiences of emotional distress and wellbeing. Over the past decade there has been an expansion of biopower through recovery orientated mental health policies and the proliferation of biomedical and psychotherapeutic treatment practices. These technologies of recovery articulate a governmental imperative to improve individual and population health by alleviating depressive symptoms, restoring chemical imbalances in the brain and reducing the 'burden of disease'. In this sense anti-depressant research, marketing, prescribing and everyday consumption is normalised as a necessary and beneficial intervention that will minimise suffering and maximise individual functioning and social productivity. With depression identified as a growing social (and gendered) problem the centrality of anti-depressant treatment has generated a range of sociological analyses of government policies, medical practices, consumer experiences and the interests of biocapital within a globalized marketplace for managing mental health (Blum and Stracuzzi, 2004; Busfield, 2006; Cohen et al., 2001; Crossley, 2003; Dowrick, 2004; Healy, 2004; Karp, 2006; Kramer, 1993; Metzl and Angel, 2004; Moynihan, 2005; Rose, 2007b).

In this article I draw upon a governmentality perspective (Foucault, 1991; Rose, 2007b) to consider the how the use of anti-depressants in the recovery process 
has been legitimised through the authority of biochemical discourses that locate depression as an individual, somatic problem. Rose (2007) suggests that the emergence of molecular science has produced new ways of understanding problems relating to mind and emotional life in terms of neurochemically deficiencies that require pharmaceutical products and psy-expertise. Yet, we know little about how individuals negotiate their recovering sense of self in relation to anti-depressant medication. Attending to the complex experiences of everyday life enables a closer analysis of the discursive repertoires that individuals mobilise in the process of constituting themselves as mentally ill, or well.

In particular I am interested in how discourses make depression thinkable in certain ways as they shape the recovery practices and subject positions available to women. To pursue this line of inquiry I draw upon select findings on anti-depressant use from a large qualitative study that explored Australian women's experiences of depression and recovery. The focus on recovery offers to shed light on the complex relation between depression and the transformation of gendered subjectivity - how are women urged to align their desires for recovery with different subject positions and ways of understanding themselves? What desires for recovery are voiced through women's narratives? I explore the significance of medication as a pharmacological technology in the everyday regimes women employed to govern their emotional distress. However, the complexity of women’s everyday recovery experiences suggests that anti-depressant use was by no means a straight forward process of medicalisation (Lupton, 1997). Rather, there was a high degree of ambivalence about medication (side effects, dependency, risk of recurrence and social critique) and women negotiated different subject positions in their desire to move out of the grip of 
depression. I do not wish to judge women's medication decisions as 'good or bad'. Nor do I want to perpetuate the sociological moralism implied in the notion that a drug free life is one that is more authentically lived. Our everyday lives are saturated with a variety of chemical substances that promise all kinds of embodied remedies, improvements and altered states. Instead, by considering how women actively exercise power and discursively constitute their depressed identities we can consider how desires are produced and negotiated around medication use. In this article I focus primarily on the subject position of the biomedical consumer who invests her hope for recovery in pharmacological solutions.

\section{The biopolitics of depression}

The work of Nikolas Rose (2003) develops a genealogy of contemporary selfhood in the age of risk and uncertainty. Rose argues that the contemporary exercise of biopower is less 'disciplinary' than Foucault previously identified in relation to the regulation of populations and bodies via the expansion of public health administration in the eighteenth century (Foucault, 1987). Relations of biopower have moved beyond the body as the focus of a clinical gaze towards a different somatic conception of subjectivity that visualizes life at the molecular level. The biopolitical regulation of populations and bodies occurs through the production and maximisation of 'life itself'. Ours is an era of vital politics in which control and self-responsibility have become integral to maximising our experience of life. Rose makes this point,

We are required to be flexible, to be in continuous training, to participate in life-long learning and perpetual assessment; we are faced with continual 
incitement to buy and to improve ourselves, urged to engage in constant monitoring of our health and never-ending risk management. In these circuits, the active citizen must engage in a constant process of modulation, adjustment, and improvement in response to the changing requirements of the practices of his or her mode of everyday life. (Rose, 2003: 430).

In relation to health, 'patients' are no longer passive recipients of expertise, they are urged to become active responsible consumers of medical services, products and pharmaceuticals. These products have emerged out of the broader transformation of knowledge within biocapitalism, science and the clinical encounter, to profoundly change the way we imagine and relate to our biological selves at the molecular level. Biocapitalism works through global circuits of exchange that bring together a range of government, research and corporate institutions, that in turn, generate profit from the creation of particular disorders that require drug treatments (Busfield, 2006; Rose, 2007b). Within mental health and illness discourses this flexible, somatic subject is rendered thinkable as neurochemically deficient via the authority of molecular science that locates disorder and dysfunction within the brain.

Rose argues (2007) that we are entering an era of neuropolitics that is shaped by this capacity to visualize problems like depression in terms of neurochemical pathways in the brain that can be acted upon by drug therapies to improve the mind. Antidepressants figure as technologies of self-improvement that require little effort or discipline other than the consumption of a pill that promises to alter our mindemotion-body relations and thus our very experience of humanness. Yet, as Blackman (2007) and others have pointed out it is impossible to separate out the biochemical 
and the cultural effects of anti-depressant use on individuals' experience of recovery. So how do individual women constitute themselves as recovering subjects in relation to the pharmacological promise of cure or treatment of depressive symptoms? What are the affective investments that women are urged to make in particular identities and explanations of their self-transformation as recovery? Next, I discuss the methodology employed in the empirical study before exploring the repertoires of recovery that are articulated through the subject position of the active biomedical consumer who relies upon anti-depressants.

\section{Women's recovery from depression project}

In Australian health policy depression is identified as the leading cause of the nonfatal burden of disease for women in Australia and prescriptions for anti-depressants have increased markedly (Australian Institute of Health and Welfare, 1999; Commonwealth Department of Health and Aged Care, 2000; Commonwealth of Australia, 2006; Outram et al., 2006). In response, a qualitative study was conducted in two eastern states of Australia with 80 women aged from 20 to 75 years who selfidentified as recovering or recovered from an experience of depression at some point in their lives. The sample included women from a number of different geographic locations that resulted in 22 rural and 58 urban participants. In-depth interviews with a semi-structured format were conducted and fully transcribed by myself and research assistants within women's homes or preferred locations. Ethical approval for the study was granted by Griffith University. Women were asked a range of questions about their experience of moving through depression, in particular, what helped and hindered their recovery. A diagnosis of depression was not required of participants 
(although the majority were diagnosed) and women responded to notices in community newspapers, fliers in health centres, email lists and radio interviews. Participants came from middle and working class backgrounds, were predominantly Anglo-Celtic, heterosexual, with a mix of mothers and non-mothers. The sample included women with a range of diagnoses from mild, moderate, major, bipolar and post-natal depression. Often there were other issues such as anxiety, panic attacks and sometimes psychosis. The participants had extensive depression related experience with $60 \%$ experiencing depression three times or more, $21 \%$ experienced $2-3$ episodes and 14\% had depression once in their lives (5\% unknown). This highlights the complex issue of recurrence or relapse that has been identified in health policy and mental health promotion initiatives for depression. Within the sample there were 72 women (90\%) who had used medication at some point in their recovery. At the time of the interview 43 (54\%) of participants were currently using anti-depressant medication and 37 (46\%) were not. The majority of participants identified themselves as 'recovering' from depression with only a few identifying as fully 'recovered'. Medication use was frequently mentioned as a signifier that one was not fully recovered from depression. In addition, the majority of participants in the study did not rely solely upon medication to assist their recovery, rather they employed a wide range of everyday practices such as social support, counselling, creating different work habits and relationships, involvement in active leisure, travel and creative pursuits.

This analysis is my interpretation of what the women said about using medication as a treatment practice and as such I do not make any claims about representativeness. Nvivo qualitative software was used to code and analyse 
comments specifically relating to anti-depressant medication. A thematic analysis was initially used to determine how women felt about the usefulness of medication in their recovery. 31 participants identified largely positive effects of medication, 24 were highly ambivalent about the effects as they spoke of benefits and drawbacks, while 19 were critical of medication either because it had negative effects on their recovery or they disliked it for a range of reasons. 6 women made no comment about medication in their interviews; half of these women had used medication and half had not. If we combine the negative and ambivalent responses it appears that over half the sample experienced antidepressant medication as problematic or felt ambivalent about its effects on their recovery. Even amongst the women who identified largely positive effects there were a range of problems identified.

The particular group of 31 women who identified anti-depressants as beneficial in their recovery exhibited some differences from those who were ambivalent or negative. For example, there were no younger women under 25 years who identified positive benefits, yet just under half the women aged 26-49 and one third of those aged over 50 years did. Of these 31 women 27 were still using antidepressants at the time of the study and the length of time that these participants had taken medication for depression ranged from six months to thirty seven years. The majority of participants over 50 years had been taking mediation for between ten and thirty seven years, and three quarters of the participants aged between 27- 49 had taken medication for up to seven years. The 31 participants were aged between 27 and 71 years and they also had extensive experience of being depressed with the majority (21/31) having between two and three or more than three episodes of depression in their lives. In addition, within this group there were proportionally more rural 
participants than in the rest of the study (11 out of 22 rural women, compared to 20/60 urban women). The implications of these sample characteristics will be further discussed in the analysis section, however, they do suggest that the length of time that some women have been active consumers of anti-depressant medication may have a significant impact on their sense of identity in relation to depression/recovery.

A second level of analysis was conducted in relation to the discursive repertoires of recovery that women participants drew upon to articulate the significance of their anti-depressant consumption. The research interview was not positioned as a vehicle for accessing the truth of women's experiences, rather it provided a means of exploring participants’ interpretative practices (Potter and Wetherell, 1987). The method of analysis brings together insights from a feminist Foucauldian approach to the discursive analysis of power-knowledge relations with a critical perspective on the interpretative practices that individuals use to make sense of their lives (Mason, 2002; Mauthner and Doucet, 2003; Moulding, 2007). This interpretative analytic moves away from polarised truth claims in research about whether medication works or not, to instead consider 'how' women constitute themselves as recovering subjects who consume or refuse anti-depressant medication by drawing upon the material-discursive resources available within an advanced liberal society. It is also a reflexive research position in the sense that I do not claim to represent the diversity of individual experiences, but rather this analysis offers a partial glimpse into complex and changing lives as they are mediated by the social world. Unlike a range of researchers who draw upon their own narratives of recovery I write from the position of not having experienced depression or recovery (Garrett, 1998). Yet, I am compelled by women's stories to understand how the otherness of 
this embodied distress is translated discursively into depression as a problem that affects the lives and opportunities of many women. In the following analysis and discussion I identify three key themes - restoring normality, signifying recovery success and the relation of control/uncertainty.

\section{Analysis and discussion}

\section{Restoring normality}

Many of the women who positively valued anti-depressants drew heavily upon the expert language of biomedicine to constitute themselves as active consumers seeking the 'right' treatment pathway towards a normalised recovery. These 31 women articulated a desire to restore their 'normality' primarily through the treatment of depression as a biochemical problem. For example, depression was most often explained in terms of genetic origins in the family or chemical imbalances in the self, and while other life events and social circumstances were often identified they were frequently positioned as secondary. The majority of women drew upon these different discourses of depression as they struggled to articulate the meaning of the recovery process and their emerging sense of self. Cathy (32 years, urban) an indigenous Australian with a complex family and cultural history described the source of her depression, 'I believe I have a predisposition to depression that's sort of genetic in my mother's side of my family'. Yet, she went on to talk in a reflective way about her desire to take medication to alleviate her 'post-natal depression' and said, 'I wouldn't say it was depression, I'd say (it was) self doubt'. The dominant stories of depression as a genetic neurochemcial problem were circulated by family members and 
importantly by the medical professionals who diagnosed and treated women experiencing emotional distress.

General practioners and psychiatrists were key sources of authority in the circulation of biochemical truths that became part of the language of self government which women adopted in their active stance towards medication use. This did not mean that participants simply did what the doctor said, rather they used biomedical expertise in their quest for recovery and self understanding. They shopped around, researched material on the Internet or in books, argued about the right dose and kind of medication, changed professionals if their requests were refused (and if others were available) and largely worked 'with' expert views of self and family life. Kaz (33 years, urban) talked about the right way to address her own neurochemical deficit,

I'm having my medication upped again. Which is to the level that I'm at now, which is fantastic. I'm not changing it. I've actually come to the conclusion, and one doctor... said this to me once, 'if you're a diabetic would you stop taking your medication because you felt good'. And I said 'No'. And she said 'Well, why would you, as a person who has a chemical imbalance in your brain, stop taking the medication, because you feel good.' I went 'Because you're not depressed anymore'. And she goes 'Yeah, but your chemical imbalance hasn't gone though'...if you're on it because you've obviously got a shortage of serotonin or something, if you are on that, you could be on it for life as maintenance. 
As active biomedical consumers women drew upon the language of diagnosis, aetiology of depression and a repertoire of recovery as primarily a process of chemical adjustment to restore normalised selfhood. The discursive formation of the depressed or recovering self was also closely aligned with the embodied effect of the drug being felt by women as largely positive, even if there were difficulties with side effects, finding the right medication and withdrawal. The relational meaning of recovery was frequently articulated through the metaphor of 'restoring balance' to the depressed subject who was understood to be lacking in brain chemicals. Jasmin (37 years, urban) talked about this when she said, 'when I'm not on medication and I'm depressed I feel like I'm already in deficit because my mind's not working properly and my brain is not working properly, so at least on medication I feel like I'm on a level playing field...so I'm not at a disadvantage for working on life's experiences'.

Anti-depressants figured as the means of redressing a neurochemical deficit that prevented women from reaching a functional 'norm' and thus helped them to maximise their potential as entrepreneurial selves. Given that most of the women identifying the positive effects of medication were aged between 26-49 years we can situate the desire to restore normality in the context of the multiple demands on women to be competent workers, citizens, consumers, partners, mothers and friends. A number of women identified this paradoxical position in which they desired medication so they could return to the very social conditions that generated feelings of distress, but as better self managers. As a mother, student and professional woman dealing with a very ill partner, Gina (36, rural) talked about how the medication enabled her to feel that she could manage competing emotional demands successfully, 'I just feel like I can react as a normal person and not get uptight about stuff, which is 
important for this (management) role that I'm in, dealing with so many staff'. The higher proportion of rural women, like Gina, who identified the positive benefits of medication was also connected to the lack of other kinds of support services available.

Participants also spoke of how they felt relieved at having their emotional distress diagnosed as depression as it transformed uncertainty and emotional distress into a rational biomedical certainty that could then be dealt with through medication management. Other researchers have also identified how a diagnosis of depression as a mental illness conferred legitimacy when women often felt that they were not taken seriously or supported by others in their work, home or health care services (Stoppard and McMullen, 2003). Relief was linked to the acquisition of scientific knowledge that one had depression, which was defined against abnormality and irrational uncertainty. In this way depression was positioned as a normalised medical category that meant women were not inherently 'crazy or abnormal' but chemically imbalanced. The anti-depressants promised to restore the feeling of being normal again - emotionally level, more evened out, less extreme reactions etc. Kaz (33 years, urban) talked about taking medication as a practice of 'doing' something to create the conditions for normality, 'I'm not doing it to feel good, I'm doing it to feel normal'. Sandy (53 years, rural) drew specifically upon the rationalities of molecular science to explain her relief that is was her brain not her 'self' that was the problem,

For the first time in my life I actually thought 'there is something wrong with me'. And that was a weight lifted off my shoulders. They explained it to me... in my case the serotonin was going across and going back quickly; not enough. 
What many depressed women like Sandy feared, and harshly judged themselves about, was being positioned as a morally weak subject who had an enduring personality problem or inability to cope with the demands of the world. Medication appeared to stem the fear of 'not coping' with the demands of modern life that was associated with depression. It is a fear of being left behind as failed individuals (gendered as poor mothers, unproductive workers, uncaring family members, unstable personalities etc) in an increasingly competitive world (Dormer, 2001; Stoppard, 2000). As the numerous comments that participants made suggest, this sense of failing to achieve the normalised parameters of successful womanhood is countered by the 'positive' effect of medication on the recovering subject's identity. The discourse of biochemical origins worked to some degree to alleviate the feelings of failure associated with the perceived abnormality of not being able to cope with life 'like everyone else'. Roslyn (43 years, urban) spoke of how depression arose in relation to this sense of failing to meet multiple gender expectations that culminated in a frightening panic attack, 'I felt a failure...I’d failed my kids...pursued my career at the expense of my family. And now I'd failed in my career and I'd failed them. For me depression and anxiety...was always something that happened to malingerers and people...who weren't strong'.

Drawing upon the psy-discourses prevalent in so many life domains women judged themselves as not 'good enough' in relation to expectations that they and others could perform consistently, effortlessly and tirelessly as superwomen - working, shopping, caring, cooking and being attractive selves. They implied that normalised femininity was premised upon unlimited embodied resources where by women always had 
emotional and physical energy available for themselves and others. Women's sense of lack or deficit was not biochemical, it was articulated through an experiential authority that signified a lack of moral and social worth. It was very difficult for women to articulate their own experiential authority about depression and recovery in relation to dominant discourses about biochemical or psychological failure. Hence, the affective investment of self in the promise of anti-depressant medication to restore ‘normality’ often co-existed uneasily alongside women’s gendered experiences of everyday life.

\section{Signifying recovery success}

What motivates the biomedical consumer is not simply a 'belief' in biomedicine but an affective investment of self in the power of medication to change the embodied relation to self. Anti-depressants can alter women's negative emotional judgements of themselves as ‘not good enough' by enabling a sense of success in recovery. Some drew upon a popular metaphor of medication as enabling a 'breathing space’ away from continual self-criticism, blame and negative comparison with others, to enable work on the self. Participants expressed a sense of achievement in relation to their use of medical expertise and this contrasted starkly with the felt failure of depression. When the anti-depressants had the desired positive effect on alleviating depressive symptoms it also signified the improvement of self that could be achieve through exercising biomedical authority. This was particularly evident in the stories of women aged over 50 who had been taking medication for many years (the longest being 37 years) and often had well established relationships with their doctors. For example, Irene (59 years, urban) had struggled with depression most of 
her life, had been hospitalised and treated with electroconvulsive therapy and had been taking various kinds of medication for 34 years when she was advised to join a new drug trial because other anti-depressants had stopped working. She spoke about this involvement enthusiastically, 'Every Thursday morning in the Mood Disorders Unit they had their big meeting in the big conference room, and of course I was going on this trial drug....and I was the topic of conversation, wasn’t I!'.

The 'successful' recovery identity performed through the ritual of medication consumption was reinforced by medical professionals, therapists and family members who were pleased to see changes. Irene described depression as an ongoing 'personal war' and medication was an expensive part of the recovery 'battle' as she had been told by two doctors that she would be taking medication (currently double the recommended rate) for the rest of her life. Yet, Irene had also employed some nonmedical practices that she felt were central in her recovery which included walking everyday with the dog and eating a balanced diet. This affective investment of self in anti-depressants is rarely considered within biomedicine beyond a vague notion of the placebo effect (Dowrick, 2004), yet it is a significant socio-cultural dimension of medication use (Blackman, 2007). Anti-depressant use was also very infrequently the single course of action that women employed in their recovery, rather it was very much intertwined with a host of everyday practices, relationships and therapies.

Participants' stories suggest that it is impossible to separate out the biochemical effect of anti-depressants on the body, the subject's own investment in this course of action and the influence of other embodied practices relating to work, leisure and relationships, and self-awareness from counselling or reflection, as they often 
occurred simultaneously. The authority invested in biomedical solutions often means that women's own efforts to make changes in their relation to self and with others remains an invisible and unrecognised. Seeking medical treatment was also a means that many women used to gain support for emotional distress that is felt as very isolating and individualising. The majority of participants talked about a range of encounters with 'good' and 'bad' doctors who were more or less responsive to their emotional needs, and many were very quick to prescribe medication whether it was desired or not.

While many women may have understood recovery as a process of rebalancing the neurochemically deficient self, many invoked a broad repertoire of recovery practices that combined exercise, relaxing leisure, different work patterns, relationships and therapeutic modalities. These non-medical practices required a different affective investment of identity and the development of an experiential source of authority that either conflicted with, or was coopted into, the biomedical discourses that women drew upon (Fullagar, 2008). The benefits of exercise, for example, were identified in relation to time for oneself, renewed pleasure in the body and social connections with others, or in terms of the effect of changing the serotonin levels in the brain. Many women developed a pragmatic approach to understanding what helped their recovery over time, and often this involved drawing upon a number of competing discourses of depression that identified social, family and biomedical sources. Most women identified the need for other changes in their lives beyond chemical adjustment although this remained a dominant frame of reference for the 27 participants still using medication. When talking about recovery many of the younger women expressed their desire to stop taking medication at some point in the future, while 
many of the older women who had been taking medication for lengthy periods of time were often resigned to taking anti-depressants for life. This difference also points towards the way older and younger women in this study articulated their depressedrecovering identity in terms of a neurochemical deficit or other identifications (social, familial etc) as they engaged with medical expertise in ways that led to 'compliance' with or resistance against the authority of doctors. This medical relationship was particularly important in mediating how women constituted their recovering subjectivities and in turn shaped the kind of pharmacological or lifestyle practices they adopted. Yet, the degree to which their own efforts to successfully create life changes were 'visible' in the medical encounter was highly variable. This theme of signifying 'success' in recovery highlights the power-knowledge relations of psychopharmacology that regulate women’s subjectivities by privileging antidepressant treatment over other recovery modalities and discourses about emotional distress.

\section{Control and Uncertainty}

For some women there was a great sense of ambivalence about the way medication signified that there was something fundamentally wrong with them because they had to take a drug to feel normal. In these cases biomedical discourses did not reduce the sense of stigma associated with depression but rather served to create evidence of 'essential' biological deficiency and by extension a lack of control over oneself. Jasmin (37 years, urban) talked about this, 
...that little pill is a reminder that there's something not quite right, and that you're a little bit dependent on something to keep you sane. So I guess there’s an aspect of your life then, that you don't have control over?

This notion of gaining self-control in recovery was characterised as a struggle for many women between their depressed and recovering identities. Depression signified feeling out of control and medication was a means of gaining control, yet antidepressants also signified the ongoing inability to control one's life or emotions. Irene (59, urban) described her spit sense of subjectivity, 'You become two persons, two people in the one body, but there's always the fear in the back of your mind that you are not standing hard enough on the other person (depressed self), and that other person is going to re-appear, just when you don't want them to'. This struggle with the otherness of self also maps across a number of oppositional relations that characterise the gendered struggle for neo-liberal selfhood - autonomy/relationality, independence/reliance, emotional strength/weakness etc (Ussher, 1991). The desire to take up the position of as an active biomedical consumer can be seen as one way of asserting control pragmatically; researching, self diagnosing, consulting with experts, monitoring progress and in the process developing a sense of expertise about one's biochemical and emotional life. A number of women spoke with great enthusiasm about their newly acquired scientific knowledge of how and why medication worked for them. However, this biomedical rationality was often underpinned by a discourse of salvation that was articulated through the investment of faith and trust in what Foucault (2007) terms the pastoral care relation with the doctor. Georgia (63, urban) had a lengthy experience of depression and suicidal tendencies and she said, 'what ever advice she (doctor) gives me I do follow it to the letter, because she has never 
failed me in 20 years...(medication) is my lifeline and I will take it every single morning because it is my lifeline'. The feeling of control that medical experts promised women through medication was, however, often elusive.

While medication helped to relieve depressive symptoms and changed the way women understood themselves as neurochemical selves, it was not unproblematic when they wanted to stop taking it. A common thread through many interviews (particularly with the older women) related to the difficult women had distinguishing between their bodily reactions when coming off medication and the return of depression like symptoms. Elisabeth talked about this difficult process of withdrawing, 'it was quite a shock when I wanted to go off medication and that's when I had terrible mood swings and I just kept crying and screaming’. Often women mentioned not being informed by their doctors about the difficulties of withdrawing from medication when it was first prescribed. Other issues identified related to the medication merry-go-round included; anti-depressants that just stopped working, constant changes of medication and dose adjustments that caused numerous side effects. These changes compounded women's feelings of being out of control with depression and ‘dependency’ on medication to feel normal. Roslyn (43 years, urban) talked about her conflicting desires,

....because they made such a difference, the medication, I'm just sort of a bit anxious about getting off them...(it's) a bit of a safety net for me...I tried to get off them once and the side affects are just horrible...the doctor who first prescribed them for me... painted a pretty rosy picture, which I think was misleading because I have suffered significant side affects trying to 
withdraw from them... (also) I think it's a psychological thing that I'm dependent on these...Am I dependent these drugs to be well, or not? It will be interesting to see.

The difficulties of stopping anti-depressant medication coexisted with participant's fears about the possible recurrence of depression at some point in the future. In relation to this fear medication consumption was articulated through rational metaphors of 'risk management' - safety nets, preparing oneself, preventing the downward spiral, weighing up the benefits and side effects. Cathy (32 years, urban) drew upon risk rationalities to explain how she used medication to surveil her emotions as a prevention strategy,

I thought as soon as I sense that something could be amiss, or that I'm at risk, like if there is a death in the family, I'll start taking medication, even if I'm not to grieved by it because maybe I might develop something, I always sort of keep watch.

The biomedical discourse about depression as a risky condition with the likelihood of recurrence lends authority to pharmacological solutions that emphasise the certainty of self-management into the future. Novas \& Rose (2000) make a key point about the way in which clinical 'risk' figures in the formation of contemporary selfhood. They argue that, 'Individuals act upon the inscriptions of clinical risk which mark their bodies and define them as particular kinds of subjects' (Novas \& Rose 2000, p. 507). Cathy's story reveals how women engage in the process of enfolding exterior discourses about biomedical and psychological risk into an interiorised notion of self 
that is deficient (Rose, 1990). Being treated for depression turns women into 'risky subjects’ marked by uncertainty, changing emotions and unruly bodies. The desire to consume medication can thus be understood as characterised by a wish for self-certain knowledge that the emotional and biochemical aspects of depression can be rationally managed. Yet, paradoxically this certainty is achieved through a chemical source external to the self that provides no guarantee of effectiveness.

The self-knowledge that arises from these risk rationalities informing anti-depressant consumption is focused largely on the medication type, dose and effects on the self. Uncertainty grew when participants considered going off medication completely or when they had to decide whether to stay on it for life - how would they cope with grief or stress in the future? What if their biochemistry had been permanently altered? What if they can’t manage at work or home with kids? Even women who had taken up biomedical discourses about medication as the true path to recovery articulated fears about how they would manage to feel in control of their emotional lives by themselves. This suggests that the emotional experience of depression and recovery exceeds and spills over the discourse about medication use as a rational risk management technique of the self. Hence, the effects of risk rationalities on how women govern themselves as biomedical consumers can be viewed in several ways. On the one hand the biochemical discourse of depression renders invisible the social conditions that give rise to its emergence in a woman's emotional life are rendered invisible or at most exist as secondary 'risk factors'. On the other, these very conditions and everyday relationships are made more visible in terms women's uncertainty about their ability to cope with emotional demands and mange oneself as a 'risky subject'. 


\section{Concluding remarks}

The dominant themes of restoring normality, signifying recovery success, and the control/uncertainty relation in the women's stories opens up a discursive space that reveals the contradictory nature of gendered discourses about depression and recovery. Anti-depressant medication generated its own fears that were very much connected to the performance of autonomous selfhood, which for many women in the study was highly problematic due to the gender relations in their lives. The majority of women in the study had experienced various forms of gendered discrimination or abuse as children and adults in the family, at work and in relationships, and/or felt enormous pressure to perform an idealised feminine, superwoman or self-sacrificing identity. Although participants tended to draw mostly upon one discursive formation, such as biomedicine, to talk about anti-depressants, they also employed other, often conflicting, discourses in their repertoires of recovery that emphasised their experiential expertise.

For many of the older women who had been on a variety of anti-depressants for many years (37 years being the longest) medication had become very much part of their identity as depressed-recovering subjects. As biomedical consumers participants drew upon the language of molecular science to explain depression, were invested in relationships with medical experts and viewed themselves primarily as neurochemically deficient selves. Although usually identified in terms of a secondary influence on women's depression, the multiple and contradictory aspects of gendered subjectivity were also played out via on going negotiations that women had with 
themselves; their past reflections, present situations and desired futures that were of course shaped by others (family, friends, experts). Even though this group of 31 women clearly identified the benefits of anti-depressant use in their everyday lives, this rational discourse was only part of the complex story of recovery. Hence, the importance of understanding the experience of depressed-recovering subjectivity as always in process, a site of struggle to assert control while making sense of uncertainty, complex emotions and normalised notions of success and failure (Weedon, 1991).

Extending Foucault's earlier work on the emergence of biopower and the disciplinary regulation of the population in the name of life and health, Rose (2007) and other governmentality theorists have begun to map out the contemporary technologies of power that 'make up’ new kinds of subjectivities. The neurochemically deficient self is one such figure who is required to exercise responsibility and self-control to restore and maximise their life potential via biomedical expertise. Yet, there has been little exploration of how this subject position is gendered in particular ways and what this might mean for women when they are diagnosed with, and treated pharmacologically for, depression.

Although biochemical discourses were a dominant source of authority in women's accounts of the benefits of anti-depressant medication this was not simply a process of medical dominance. Rather, anti-depressant consumption was part of the process of subjectification that characterises the feminine subject's exercise of freedom through the negotiation of competing discourses (Rose, 1996; Rose, 2007a). This process of constituting selfhood involved a host of complex relations from compliance with 
biochemical explanations of depression, to resistance against expert forms of authority and truth. Through taking up the subject position of the biomedical consumer women in this study exercised agency through becoming active partners in the new modalities of brain science and psy-expertise. In this way women were not simply passive recipients of expert knowledge, rather they were obliged align their desire to restore 'balance' and reduce the risk of recurrence of depression with biochemical management. This recovery pathway positions women within a network of professional surveillance and authority that renders invisible the context of gendered power relations and emotional distress that exist beyond the discursive parameters of molecular science. By seeking biochemical solutions to their somatic problems women repeatedly enacted the culturally valued desire to become 'good' women, since brain chemistry was the problem not social norms or the organisation of gender relations. Yet, despite the dominance of biomedical accounts very few women attributed their recovery solely to medication or understood depression as singularly caused by a chemical imbalance. Most women struggled to negotiate different discourses about depression as they tried to make sense of their emotional lives, symptoms and changing bodies as well as the connection between depression and their everyday relationships with others, and importantly with themselves - their self worth, their identity as women, mothers, workers, partners and their past and or future lives.

There were competing discourses about depression as a social and psychological problem that were connected to women's feeling of being a failed moral subject - not good enough daughters, mothers, wives, workers, friends etc. Anti-depressants appeared to have an effect on women's critical relation with themselves - low self 
worth, high expectations, over responsibility, perfectionist or self-blaming relations were identified as contributing to undermining women's desire for autonomy and connection with others. Depression, and the anti-depressants themselves, also signified women's inability to achieve the normal of moral and successful selfhood. Hence, we can see the seductive power of biomedical explanations that reconfigure the problem of unsuccessful womanhood as a neurochemical problem that can be expertly and rationally managed. The women's stories articulate the struggle to reconcile their desires to be fully recovered with their on going medication use.

To return to Rose's (2007) argument that subjectivity is increasingly constituted in somatic terms through the rise of neurochemical discourses, I suggest that discourses of depression work in a paradoxical way to govern the emotional lives of women. Pharmacological technologies promise to restore certainty, normal function, control and hence autonomy to the feminised entrepreneurial subject with multiple gendered responsibilities. However, they also undermine self-certainty and generate fears about the recurrence of depression and the loss of autonomy through chemical dependency.

The variety of recovery practices and affective investments in different sources of identity is something that conventional medical practices often overlook in privileging medication in the recovery process. This also raises the issue of how women may privilege the power of medication at the expense of acknowledging their own efforts in dealing with depression. This may indeed prevent the exploration and provision of a range of non-medical alternatives. Either in conjunction with, or contrast to, biomedical discourses of depression, participants drew upon their own experiential authority to identify a range of recovery practices they used to work on themselves, to 
be health promoting and responsible subjects. These included, eating, sleeping and exercising well, changing work-home patterns \& relationships, as well as their own habits of being hard on themselves for not managing everything alone or perfectly. These stories point to the impossibility of separating the mind-body, individual-social and medical-everyday practices and relationships as they effect and affect women's experience of recovery. While pharmaceutical studies may refer to these other experiences as a placebo effect, they are in fact attributable to an experiential authority that women have developed through their everyday negotiation of neurochemically defined selfhood. However, it is a source of authority that remains largely unacknowledged by medical professionals who privilege the power of molecular science to identify and overcome the complexity of emotional distress.

\section{References}

Australian Institute of Health and Welfare (1999). National health priority areas report: mental health a report focusing on depression 1998. Canberra: Department of Health and Aged Care, Australian Institute of Health and Welfare.

Blackman, L. (2007). Psychiatric culture and bodies of resistance. Body and Society, $13,1-23$.

Blum, L. and Stracuzzi, N. (2004). Gender in the Prozac nation: Popular discourse and productive femininity. Gender and Society, 18, 269-286.

Busfield, J. (2006). Pills, power, people: Sociological understandings of the pharmaceutical industry. Sociology, 40, 297-314.

Cohen, D., McCubbin, M., Collin, J. and Perodeau, G. (2001). Medications as social phenomenon. Health, 5, 441-469.

Commonwealth Department of Health and Aged Care (2000). National Action Plan for Depression 1998-2003. Canberra: AIHW \& CDHAC.

Commonwealth of Australia (2006). Select Committee on Mental Health: A national approach to mental health - from crisis to community (pp. 594). Canberra: Senate Select Committee.

Crossley, N. (2003). Prozac nation and the biochemical self: A critique. In S. Williams, Burke, L, Bendelow, G (Ed.), Debating biology: Sociological reflections on health, medicine and society (245-258). London: Routledge.

Dormer, S., Davies, B (2001). Desiring women and the (im)possibility of being. Australian Psychologist, 36, 4-9. 
Dowrick, C. (2004). Beyond depression: A new approach to understanding and management. Oxford: Oxford University Press.

Foucault, M. (1987). The history of sexuality, volume 1, An introduction. Harmondsworth: Penguin.

Foucault, M. (1991). Governmentality. In G. Burchell, Gordon, G and Miller, P (Ed.), The Foucault effect: Studies in governmentality. Hemel Hempstead: Harvester Wheatsheaf.

Foucault, M. (2007). Security, territory, population, Lectures at the College de France 1977-1978. Hampshire: Palgrave Macmillan.

Fullagar, S. (2008). Leisure practices as counter-depressants. Leisure Sciences, 1-18.

Garrett, C. (1998). Beyond Anorexia: Narrative, spirituality and recovery. Cambride: Cambridge University Press.

Healy, D. (2004). Let them eat Prozac: The unhealthy relationship between the pharmaceutical industry and depression. New York: New York University Press.

Karp, D. (2006). Is it me or my meds? Living with anti-depressants. Cambridge: Harvard University Press.

Kramer, P. (1993). Listening to Prozac. New York: Viking.

Lupton, D. (1997). Foucault and the medicalisation critique. In A. a. B. Peterson, R. (Ed.), Foucault, health and medicine (94-110). London: Routledge.

Mason, G. (2002). The Spectacle of Violence: Homophobia, Gender and Knowledge. London: Routledge.

Mauthner, N. and Doucet, A. (2003). Reflexive accounts and accounts of reflexivity in qualitative data analysis. Sociology, 37, 413-431.

Metzl, J. and Angel, J. (2004). Assessing the impact of SSRI antidepressants on popular notions of women's depressive illness. Social Science and Medicine, 58, 577-584.

Moulding, N. (2007). "Love your body, move your body, feed your body": Discourses of self-care and social marketing in a body image health promotion program. Critical Public Health, 17, 57 - 69.

Moynihan, R. a. C., A (2005). Selling sickness: How drug companies are turning us all into patients. Sydney: Allen and Unwin.

Novas, C. and Rose, N. (2000). Genetic risk and the birth of the somatic individual. Economy and Society, 29, 485-513.

Outram, S., Murphy, B. and Cockburn, J. (2006). Prevalence of and factors associated with midlife women taking medicines for psychological distress. Australian eJournal for the Advancement of Mental Health, 5, 1-13.

Potter, J. and Wetherell, M. (1987). Discourse and social psychology: Beyond attitudes and behaviour. London: Sage.

Rose, N. (1990). Governing the soul: The shaping of the private self. London: Routledge.

Rose, N. (1996). Inventing ourselves: Psychology, power and personhood. Cambridge: Cambridge University Press.

Rose, N. (2003). The neurochemical self and its anomalies. In R. Ericson and A. Doyle (Eds.), Risk and Morality (407-437). Toronto: University of Toronto Press.

Rose, N. (2007a). Molecular biopolitics, Somatic ethics and the spirit of biocapital. Social Theory and Health, 5, 3-30.

Rose, N. (2007b). The Politics of Life Itself: Biomedicine, power and subjectivity in the twenty-first century. Princeton: Princeton University Press. 
Stoppard, J. (2000). Understanding depression: Feminist social constructionist approaches. London: Routledge.

Stoppard, J. and McMullen, L. (2003). Situating sadness: Women and depression in social context (pp. 228). New York: New York University Press.

Ussher, J. (1991). Women's madness: Misogyny or mental illness? New York: Havester Wheatsheaf.

Weedon, C. (1991). Feminism and Post-structuralist Theory. London: Routledge.

\section{$\underline{\text { Bionotes }}$}

Simone Fullagar is an interdisciplinary sociologist with a post-structuralist interest in health, well-being and leisure practices. She is currently completing a large qualitative study on women's recovery from depression that was funded by the Australian Research Council.

\section{$\underline{\text { Acknowledgements }}$}

I would like to acknowledge the women who generously contributed their time and enthusiasm to the project and the Australian Research Council for funding from 20052007. Thanks also to Wendy O’Brien and Margaret Ward for their research assistance. 